\title{
Reduction of subacromial osteolysis by bending the hook arthroscopically in clavicle hook plate fixation for distal clavicle fractures
}

Atsushi Okazaki ( $\square$ okz@myad.jp )

Hiratsuka Kyosai Hospital

Hiroaki Sakano

Hiratsuka Kyosai Byoin

Tsuyoshi Takeuchi

Yokohama Municipal Citizen's Hospital

Yutaka Inaba

Yokohama City University of Medicine

Research article

Keywords: Clavicle hook plate, Distal clavicle fracture, Subacromial osteolysis, Arthroscopy, Bending of the hook

Posted Date: January 28th, 2020

DOI: https://doi.org/10.21203/rs.2.22036/v1

License: (c) (i) This work is licensed under a Creative Commons Attribution 4.0 International License. Read Full License 


\section{Abstract}

Background: Subacromial osteolysis is a serious complication caused by clavicle hook plates. Incongruency between the hook and undersurface of the acromion has been reported as a cause of subacromial osteolysis. The aim of this study was to retrospectively examine the effectiveness of hook bending in reducing subacromial osteolysis.

Methods: Twenty-two patients with unstable distal clavicle fractures were treated with clavicle hook plates. There were 19 males and 3 females, with a mean age of 55.0 years. They were followed for a mean period of 9.5 months. The patients were divided into two groups; there were 10 patients whose hook was bent (the bending group) and 12 patients whose hook was not bent (the nonbending group). In the bending group, the hook was bent using a dedicated bender such that the hook and the undersurface of the acromion were parallel, and the direction of the hook was confirmed arthroscopically. At plate removal, arthroscopy was performed in both groups to observe the subacromial bony defect and the rotator cuff injury.

Results: One patient in the nonbending group had a fibrous union, but bone union was achieved in all other patients. In the bending group, the angle at which the hook was inclined downward with respect to the distal portion of the plate (hook inclination angle) was $9.3 \pm 6.1^{\circ}$ (range, $2-23^{\circ}$ ). The subacromial bony defects were significantly smaller in the bending group $(1.7 \pm 2.4 \mathrm{~mm})$ than in the nonbending group (4.7 $\pm 2.3 \mathrm{~mm})(P<0.05)$. Partial-thickness rotator cuff tears localized around the hook were observed arthroscopically in 6 patients in the bending group (60\%) and in 7 patients in the nonbending group $(58 \%)$.

Conclusions: When the hook was bent such that it was parallel to the undersurface of the acromion, the degree of subacromial osteolysis was reduced.

\section{Background}

Clavicle hook plates used for the treatment of distal clavicle fractures provide strong fixation, and the surgical procedure is relatively easy to perform. However, complications such as subacromial osteolysis and rotator cuff injury due to the hook have been reported [1-11]. The hook portion of the clavicle hook plate is placed under the acromion, and downward pressure is applied from the plate portion on the clavicle to reduce the fracture. Pressure is continuously applied to the undersurface of the acromion after the operation to suppress the upward dislocation of the distal end of the clavicle, and this pressure has been shown to cause subacromial osteolysis [2-4,6-10]. If the severity of subacromial osteolysis progresses significantly, a serious complication, acromial fracture, occurs [12-14]. There is a report recommending the locking plate because the complication rate of the clavicle hook plate is higher than that of the locking plate [15-17]. However, there are cases for which a clavicle hook plate must be used, such as cases involving a highly comminuted distal bone fragment. Therefore, it is important to take measures to reduce complications so that the clavicle hook plate can be used safely. 
When only the tip of the hook is in contact with the undersurface of the acromion and the stress is concentrated at one point, the severity of subacromial osteolysis progresses. If the hook is bent to be parallel to the undersurface of the acromion, the contact area between the hook and the acromion increases, and the pressure disperses. We hypothesized that subacromial osteolysis can be suppressed by bending of the hook. To assess the state of subacromial osteolysis, the subacromial bony defect was quantitatively assessed arthroscopically at plate removal. In this article, we examined the effect of hook bending on subacromial osteolysis by comparing groups with and without hook bending.

\section{Methods}

Twenty-two patients with unstable distal clavicle fractures who underwent surgical treatment with clavicle hook plates were evaluated retrospectively. There were 19 males and 3 females, with a mean age of 55.0 years (range, 32-77 years). The right shoulder was treated in 13 patients, and the left shoulder was treated in 9 . The mechanism of injury was a fall in 19 patients and a traffic accident in 3 . The fracture types according to the Craig classification were type IIA in 11 patients, type IIB in 9 , and type $V$ in 2 [18]. The patients were followed for a mean period of 9.5 months (range, 5.1-20.3 months). The patients were divided into two groups; there were 10 patients whose hook on the plate was bent such that the hook was parallel to the undersurface of the acromion (the bending group) and 12 patients whose hook was not bent (the nonbending group). The patients in the bending group were treated with an HTS clavicular plate (HOYA Technosurgical Corporation, Tokyo, Japan; Fig. 1A), which has a hook that can be bent at the base using a dedicated bender (arrow in Fig. 1A, Fig. 2). This plate was made commercially available in March 2015 and is the only clavicle hook plate that has a dedicated hook bender. The patients in the nonbending group were treated with a different clavicle hook plate (DePuy Synthes, West Chester, USA; Fig. 1B). The bending group consisted of cases consecutively included from June 2017 to January 2019 and was compared with the nonbending group, which included cases consecutively included from May 2006 to September 2007, and there were no patients lost to follow-up in either group.

The patients were placed in the beach chair position under general anesthesia. The skin incision was made from the center of the clavicle shaft toward the hook insertion point, which was posterior to the acromioclavicular joint. The depth of the hook was determined using fluoroscopy and trial implants intraoperatively. The hook was passed under the acromion, and the plate was placed on the clavicle. If necessary, the plate portion was bent according to the shape of the clavicle. In the bending group, subacromial arthroscopy was performed at this point. The hook was bent by the dedicated bender such that the hook and the undersurface of the acromion were parallel, and the direction of the hook was confirmed arthroscopically. The hook inclination angle was measured as the angle at which the hook was inclined downward with respect to the distal portion of the plate (Fig. 3). In the nonbending group, arthroscopy and the bending of the hook were not performed. Screws were inserted to secure the plate to the clavicle.

Postoperatively, the patients used a sling for several days and then started a range of motion exercise. The patients were instructed to restrict flexion and abduction of the shoulder to $90^{\circ}$ until the plate was 
removed. The plates were removed after radiographs showed bone union. At plate removal, arthroscopy was performed for both groups to observe the subacromial bony defect and rotator cuff injury. In addition, we evaluated the level of pain, shoulder joint range of motion, Constant-Murley score at the follow-up, and postoperative complications [19]. Statistical analysis was performed using the unpaired Student's t-test, and a P-value of less than 0.05 was considered to be statistically significant.

\section{Results}

One patient in the nonbending group had a fibrous union, but bone union was achieved in all other patients. The duration from the operation to plate removal was $4.2 \pm 1.0$ months (range, 3.3-5.9 months) in the bending group and $5.1 \pm 1.5$ months (range, 3.5-8.5 months) in the nonbending group. In the bending group, the hook inclination angle was $9.3 \pm 6.1^{\circ}$ (range, $2-23^{\circ} ;$ Fig. 4). Fig. 4 shows a histogram of the hook inclination angle for the patients in the bending group. The hook inclination angle was most commonly between 6 and 10 degrees. Before plate removal, subacromial osteolysis was observed radiographically in 2 patients in the bending group (20\%) and in 6 patients in the nonbending group (50\%). However, after plate removal, subacromial osteolysis was revealed in 5 patients (50\%) and in 11 patients (92\%) in the bending and nonbending groups, respectively. Shoulder pain at the last follow-up was observed in 2 patients in the bending group (20\%) and 2 patients in the nonbending group (17\%), all of which were mild. All patients had resumed normal activities. At the last follow-up, the flexion ranges of motion in the operative shoulder were $148.0 \pm 26.6^{\circ}$ and $152.5 \pm 38.0^{\circ}$, the abduction ranges of motion were $156.0 \pm 27.2^{\circ}$ and $155.0 \pm 36.6^{\circ}$, and the external rotation ranges of motion were $46.5 \pm 55.8^{\circ}$ and $45.8 \pm 76.5^{\circ}$ in the bending group and the nonbending group, respectively; the internal rotation range of motion was up to L3 in both groups. At the last follow-up, the Constant-Murley score was $90.0 \pm 4.2$ points in the bending group and $91.3 \pm 3.1$ points in the nonbending group. There was no significant difference in the range of motion or Constant-Murley score between groups.

The subacromial bony defects due to the hook observed arthroscopically at plate removal were significantly smaller in the bending group $(1.7 \pm 2.4 \mathrm{~mm})$ than in the nonbending group $(4.7 \pm 2.3 \mathrm{~mm})(\mathrm{p}$ $<0.05)$. In particular, the number of patients with a subacromial bony defect of $1 \mathrm{~mm}$ or smaller was 6 patients in the bending group (60\%) and 1 patient in the nonbending group (8.3\%). At plate removal, partial-thickness rotator cuff tears localized around the hook were observed arthroscopically in 6 patients

in the bending group $(60 \%)$ and in 7 patients in the nonbending group (58\%). There were no full-thickness rotator cuff tears in either group. There were no complications, such as infection, neurovascular injury, nonunion, acromial fracture, or plate breakage. General information for the 22 patients is shown in Table 1, and a typical case is shown in Fig. 5 and Fig. 6.

\section{Discussion}

Subacromial osteolysis and rotator cuff injury caused by the hook are serious complications caused by clavicle hook plates, and there are many reports of these complications [1-11]. An inappropriate hook 
depth and incongruency between the hook and undersurface of the acromion have been reported as causes of subacromial osteolysis [20-23].

If the hook depth is too short, the pressure applied to the acromion by the hook will increase and cause subacromial osteolysis [22, 23]. Lee et al. used finite element analysis (FEA) and found that deeper implantation of the hook reduces the force applied to the acromion by the hook [22]. However, if the hook depth is too long, the hook will make contact the rotator cuff, causing impingement syndrome or rotator cuff injury $[1,3,5,8,11]$. It is important to select the appropriate hook depth to prevent these complications.

According to previous reports about the morphology of the acromioclavicular joint, there are many patients whose acromion is inclined downward with respect to the distal end of the clavicle in the coronal plane [6, 24]. The hook portion of the clavicle hook plate forms a right angle and does not match the shape of the acromion. Therefore, when the clavicle hook plate is installed on a patient whose acromion is inclined downward, only the tip of the hook comes into contact with the acromion. Shen et al. reported that bending of the hook is necessary to increase the contact area between the hook and the acromion because an increased acromioclavicular angle promotes osteolysis [6]. Li et al. compared clavicle hook plates with hook angles of 0 and 15 degrees and reported that patients treated with the 15-degree hook plate had less severe pain and better postoperative recovery than those treated with the 0 -degree clavicle hook plate [25]. Hung et al. reported that the more the hook was inclined downward, the more proximal the contact position between the hook and the acromion [20]. Based on the above results, we hypothesized that subacromial osteolysis can be reduced by bending the hook downward.

Since the angle between the acromion and the distal end of the clavicle varies greatly, the appropriate bending angle of the hook varies from case to case. In our study, there were individual differences in the hook inclination angle, which ranged from 2 to 23 degrees and was directed downward. It is necessary to determine the appropriate hook bending angle for each patient. Hyun et al. reported that subacromial osteolysis can be reduced by bending the hook using a fluoroscopic view obtained by directing the X-ray beam from the anterior to posterior direction at approximately 30 to 40 degrees caudally [4]. However, Lee et al. reported that arthroscopy is necessary because fluoroscopic assessments cannot be used to accurately evaluate the presence of impingement of the hook and the rotator cuff [2]. In our study, even when the hook was bent arthroscopically such that the hook was parallel to the acromion, there were some cases in which the hook and the acromion did not appear parallel in the fluoroscopic view. The reason for the difficulty in determining the proper fluoroscopic direction is that the position of the hook relative to the acromion differs depending on the patient. ElMaraghy et al. reported that the posterior hook implantation angle varied widely, ranging from $0^{\circ}$ to $67^{\circ}$, from the midline toward the posterior aspect of the acromion [26]. According to the above results, arthroscopy was more useful than fluoroscopy in bending the hook accurately such that it was parallel with the acromion.

The width of the hook of the Synthes clavicle hook plate is $5.2 \mathrm{~mm}$. To avoid hook breakage, the surgical technique manual provided by the manufacturer recommends not bending the hook more than 10 to 15 
degrees. However, the hook of the HOYA HTS clavicular plate is bent at the base of the hook (arrow in Fig. 1A) using a dedicated bender. The width of the hook tip is $5.2 \mathrm{~mm}$, but the width of the portion to be bent is $7.46 \mathrm{~mm}$; therefore, it is difficult to break the hook, even when it is bent. In the mechanical tests conducted by the manufacturer, the hook of the HOYA HTS clavicular plate did not break, even when the hook was bent 17.5 degrees downward and a force of $200 \mathrm{~N}$ was applied to the hook from the top $1,000,000$ times. Since bending the hook back and forth many times may cause the hook to break, we did not bend it in the reverse direction.

In previous reports, X-ray or computed tomography (CT) was commonly used to evaluate subacromial osteolysis [2, 4, 6-10]. However, it is difficult to accurately evaluate subacromial osteolysis. The radiolucent area cannot be evaluated accurately when the hook and the radiolucent area overlap in X-rays or hook artifacts appear in CT scans. In our study, there were patients in which osteolysis was revealed after plate removal, even though osteolysis was not visible before plate removal. We quantitatively assessed the subacromial bony defects by performing subacromial arthroscopy at plate removal. Using arthroscopy, the effect of hook bending on subacromial osteolysis could be accurately evaluated.

Rotator cuff injury is also a serious complication that is caused by the hook [1, 3, 5, 11]. Gu et al. reported that the rotator cuff and shoulder joint capsule can impinge with the hook if the hook is placed deeply or the subacromial space is small [1]. Lee et al. arthroscopically confirmed the presence of impingement of the rotator cuff and the hook, and a plate with a different hook depth was used or the hook portion was bent if impingement was identified [2]. We predicted that rotator cuff injury can be prevented by bending the hook to be parallel to the undersurface of the acromion. However, the degree of rotator cuff injury in the bending group was not different from that in the nonbinding group. Deng et al. reported that since most hook plates do not match the shape of the shoulder exactly, the hook depth is longer than the thickness of the acromion, then subacromial space is narrowed by the hook [27]. We considered that some degree of rotator cuff injury was inevitable when using the clavicle hook plate. Fortunately, although partial-thickness rotator cuff tears were observed, there were no patients with complete rotator cuff tears. There are reports showing symptom improvement without special treatment after plate removal, even in patients who exhibited pain due to the hook $[1,2,5,17]$. We considered that localized injury of the rotator cuff surface can be naturally repaired by plate removal. Additional studies are needed to accurately determine the complications caused by the hook.

There were several limitations to this study. Our study was retrospective and nonrandomized, and the sample size was small. Furthermore, different plates were used for the bending group and the nonbending group. Therefore, the difference in the degree of subacromial osteolysis may be affected by factors other than hook bending.

\section{Conclusions}

By bending the hook so that it was parallel to the undersurface of the acromion, the degree of subacromial osteolysis was reduced. However, there was little difference in the degree of rotator cuff 
injury with or without hook bending. Subacromial arthroscopy was more useful than fluoroscopy in bending the hook accurately.

\section{List Of Abbreviations}

CT (computed tomography), FEA (finite element analysis)

\section{Declarations}

Ethics approval and consent to participate: Informed consent was obtained from each patient, and appropriate institutional review board approval was obtained prior to case review.

Consent for publication: Not applicable.

Availability of data and materials: The datasets used and analyzed during the current study are available from the corresponding author upon reasonable request.

Competing interests: The authors declare that they have no competing interests.

Funding: None.

Authors' contributions: AO designed this study, performed the statistical analysis and drafted the manuscript. TT assisted in conducting the arthroscopic evaluation. HS and YI helped draft the manuscript. All authors read and approved the final manuscript.

Acknowledgements: We would like to acknowledge the professional manuscript services of Springer Nature Author Services.

\section{References}

1. Gu X, Cheng B, Sun J, Tao K. Arthroscopic evaluation for omalgia patients undergoing the clavicular hook plate fixation of distal clavicle fractures. J Orthop Surg Res. 2014;9:46.

2. Lee KW, Lee SK, Kim KJ, Kim YI, Kwon WC, Choy WS. Arthroscopic-assisted locking compression plate clavicular hook fixation for unstable fractures of the lateral end of the clavicle: a prospective study. Int Orthop. 2010;34(6):839-45.

3. Chandrasenan J, Badhe S, Cresswell T, De beer J. The Clavicular Hook Plate: Consequences in Three Cases. Eur J Trauma Emerg Surg. 2007;33(5):557-9.

4. Yoon-Suk Hyun, Gab-Lae Kim, Sang-Min Choi, Woo-Jin Shin, Dong-Yeon Seo: A Novel Fluoroscopic View for Positioning the AO Clavicle Hook Plate Decreases Its Associated in situ Complications. Clinics in Shoulder and Elbow. 2016;19(1):25-32

5. Lin HY, Wong PK, Ho WP, Chuang TY, Liao YS, Wong CC. Clavicular hook plate may induce subacromial shoulder impingement and rotator cuff lesion--dynamic sonographic evaluation. $J$ 
Orthop Surg Res. 2014;9:6.

6. Shen PC, Zhu Y, Zhang H, et al. Three-dimensional morphological analysis of acromioclavicular joint in patients with and without subacromial erosion after hook plate fixation. J Int Med Res 2018; 46; 511-521.

7. Sun S, Gan M, Sun H, Wu G, Yang H, Zhou F. Does Subacromial Osteolysis Affect Shoulder Function after Clavicle Hook Plating?. Biomed Res Int. 2016;2016:4085305.

8. Tiren D, Van bemmel AJ, Swank DJ, Van der linden FM. Hook plate fixation of acute displaced lateral clavicle fractures: mid-term results and a brief literature overview. J Orthop Surg Res. 2012;7:2.

9. Senthil Loganathan, Shenbaghavalli Thanikaimalai, Jambu Nageshwaran, Samuel Chittaranjan: Clavicle Hook Depth and Impingement Syndrome-A Cause-Effect Relationship. Open Journal of Orthopedics. Open Journal of Orthopedics. 2017: 07(01):1-6

10. Lopiz Y, Checa P, García-fernández C, Valle J, Vega ML, Marco F. Complications with the clavicle hook plate after fixation of Neer type II clavicle fractures. Int Orthop. 2019;43(7):1701-1708.

11. Lin HY, Wong PK, Ho WP, Chuang TY, Liao YS, Wong CC. Clavicular hook plate may induce subacromial shoulder impingement and rotator cuff lesion--dynamic sonographic evaluation. J Orthop Surg Res. 2014;9:6.

12. Tamiya H, Umemoto S, Akimoto Y, Kyo T, Gamo K, Kuratsu S. Posterior Positioning of a Clavicle Hook Plate Is a Risk Factor for Acromial Fractures after Acromioclavicular Joint Dislocation. Open Journal of Orthopedics. 2019;9(4):101-111.

13. Chen CY, Yang SW, Lin KY, et al. Comparison of single coracoclavicular suture fixation and hook plate for the treatment of acute unstable distal clavicle fractures. J Orthop Surg Res. 2014;9:42.

14. Kashii M, Inui H, Yamamoto K. Surgical treatment of distal clavicle fractures using the clavicular hook plate. Clin Orthop Relat Res. 2006;447:158-64.

15. Zhang C, Huang J, Luo Y, Sun H. Comparison of the efficacy of a distal clavicular locking plate versus a clavicular hook plate in the treatment of unstable distal clavicle fractures and a systematic literature review. Int Orthop. 2014;38(7):1461-8.

16. Erdle B, Izadpanah $\mathrm{K}$, Jaeger $\mathrm{M}$, et al. Comparative analysis of locking plate versus hook plate osteosynthesis of Neer type IIB lateral clavicle fractures. Arch Orthop Trauma Surg. 2017;137(5):651662.

17. Tan HL, Zhao JK, Qian C, Shi Y, Zhou Q. Clinical results of treatment using a clavicular hook plate versus a T-plate in neer type II distal clavicle fractures. Orthopedics. 2012;35(8):e1191-7.

18. Craig, EV. "Fractures of the clavicle". The shoulder. Rockwood CA Jr, Matsen FA 囚. ed. Philadelphia, WB Saunders, 1990, 367-412】

19. Constant CR, Murley AH. A clinical method of functional assessment of the shoulder. Clin Orthop Relat Res. 1987; 214; 160-164.

20. Hung LK, Su KC, Lu WH, et al. Biomechanical analysis of clavicle hook plate implantation with different hook angles in the acromioclavicular joint. Int Orthop. 2017; 41; 1663-1669. 
21. Yoon JP, Lee YS, Song GS, et al. Morphological analysis of acromion and hook plate for the fixation of acromioclavicular joint dislocation. Knee Surg Sports Traumatol Arthrosc. 2017;25; 980-986.

22. Lee CH, Shih CM, Huang KC, Chen KH, Hung LK, Su KC. Biomechanical Analysis of Implanted Clavicle Hook Plates With Different Implant Depths and Materials in the Acromioclavicular Joint: A Finite Element Analysis Study. Artif Organs. 2016;40(11):1062-1070.

23. Shih CM, Huang KC, Pan CC, Lee CH, Su KC. Biomechanical analysis of acromioclavicular joint dislocation treated with clavicle hook plates in different lengths. Int Orthop. 2015;39(11):2239-44.

24. Macgillivray JD, Fealy S, Potter HG, O'brien SJ. Multiplanar analysis of acromion morphology. Am J Sports Med. 1998;26(6):836-40.

25. Li G, Liu T, Shao X, et al. Fifteen-degree clavicular hook plate achieves better clinical outcomes in the treatment of acromioclavicular joint dislocation. J Int Med Res. 2018;46(11):4547-4559.

26. Elmaraghy AW, Devereaux MW, Ravichandiran K, et al. Subacromial morphometric assessment of the clavicle hook plate. Injury. 2010; 41; 613-619.

27. Deng Z, Cai L, Ping A, Ai Q, Wang Y. Anatomical research on the subacromial interval following implantation of clavicle hook plates. Int J Sports Med. 2014;35(10):857-62.

\section{Table}

Please see the supplementary files section to access the table.

\section{Figures}



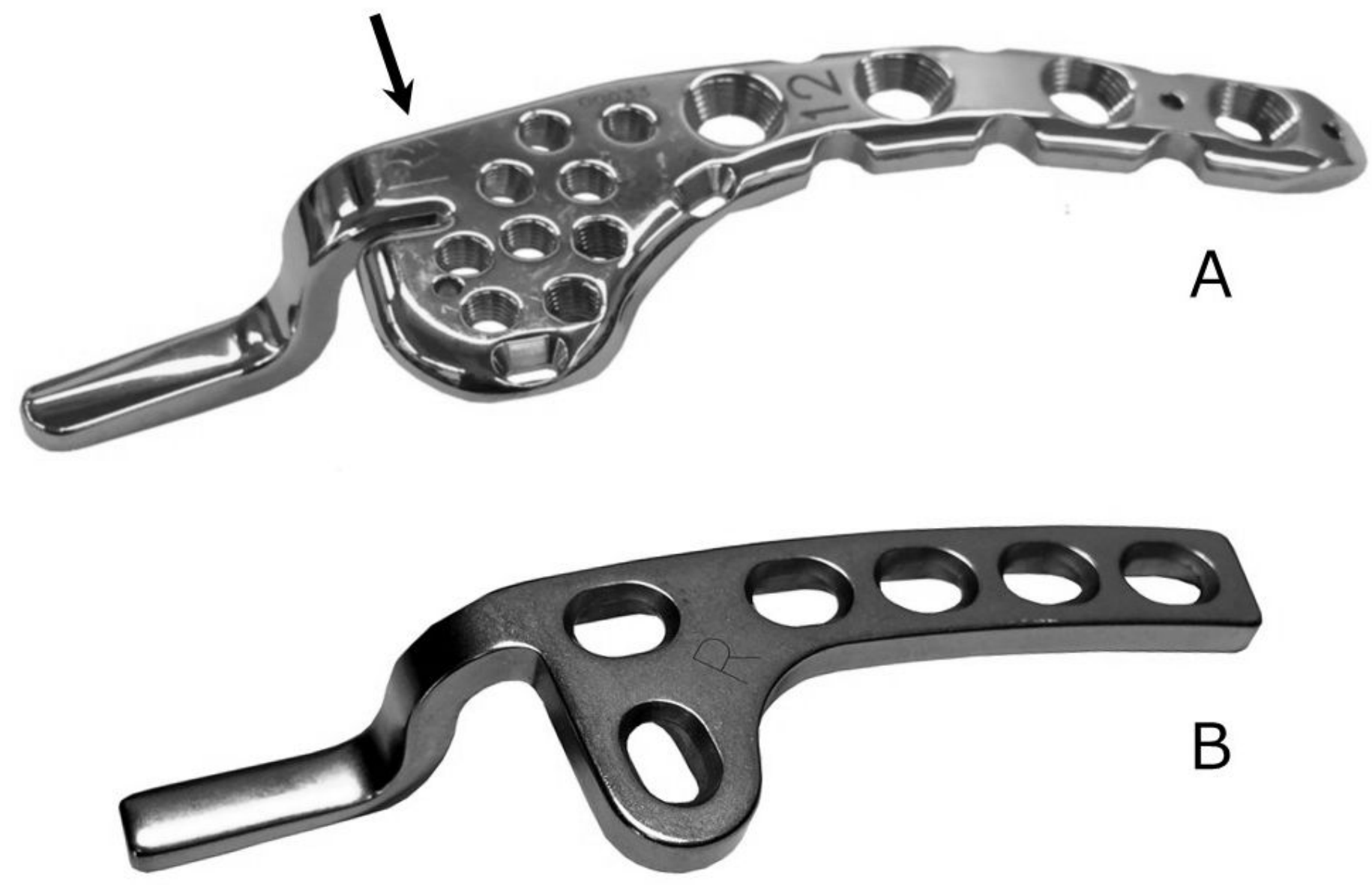

Figure 1

(A) HTS clavicular plate (bending group). The hook is bent at the base of the hook (arrow). (B) Clavicle hook plate (nonbending group). 


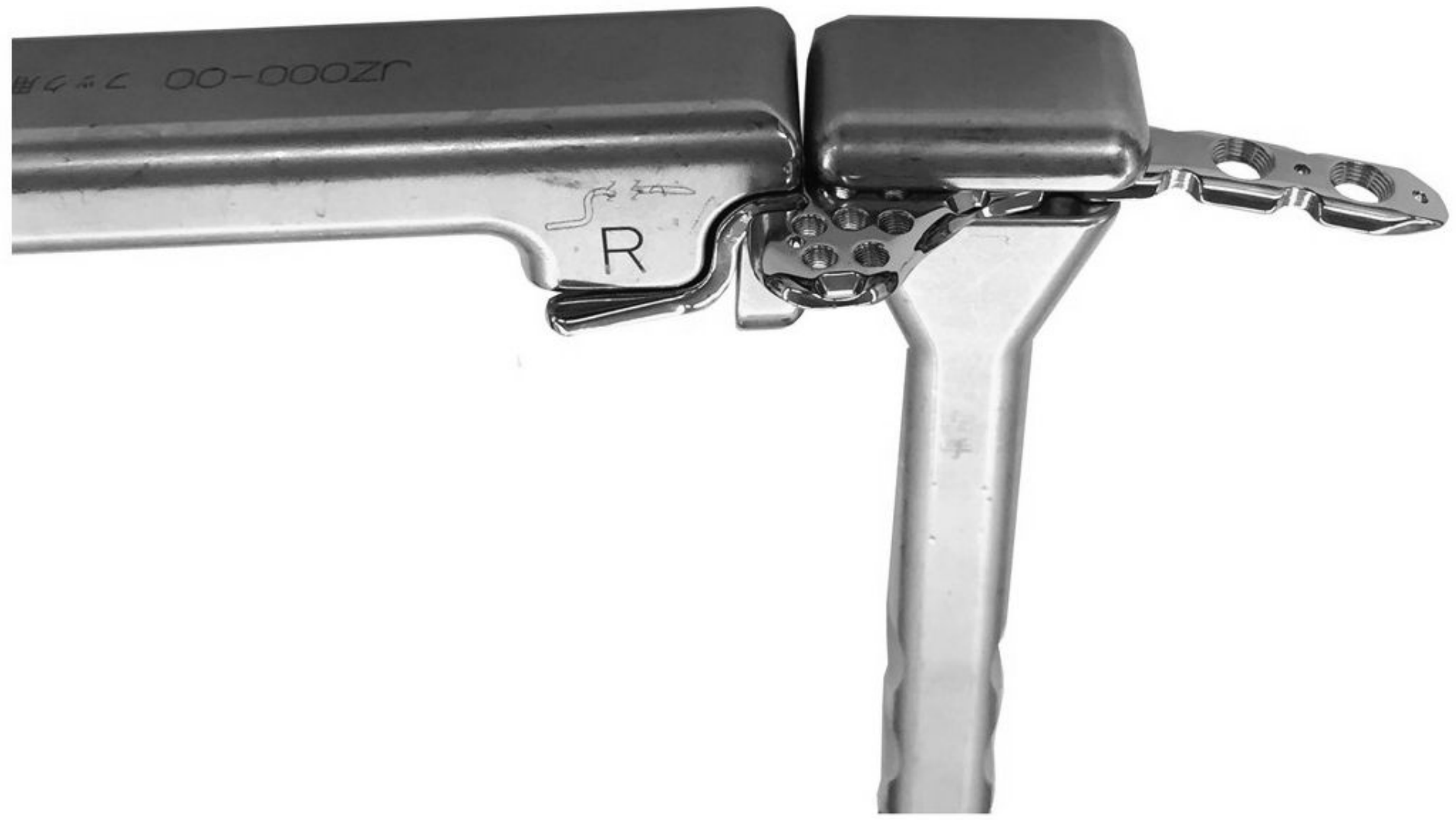

Figure 2

HTS clavicular plate is bent using a dedicated bender.

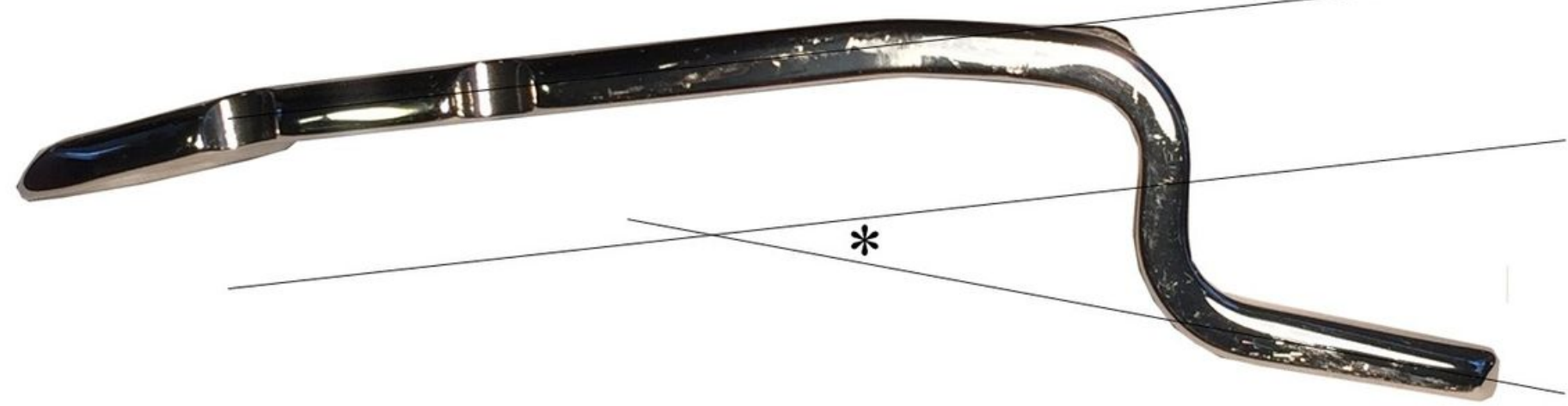

Figure 3

Hook inclination angle. The angle at which the hook was inclined downward with respect to the distal portion of the plate $\left.{ }^{*}\right)$. 


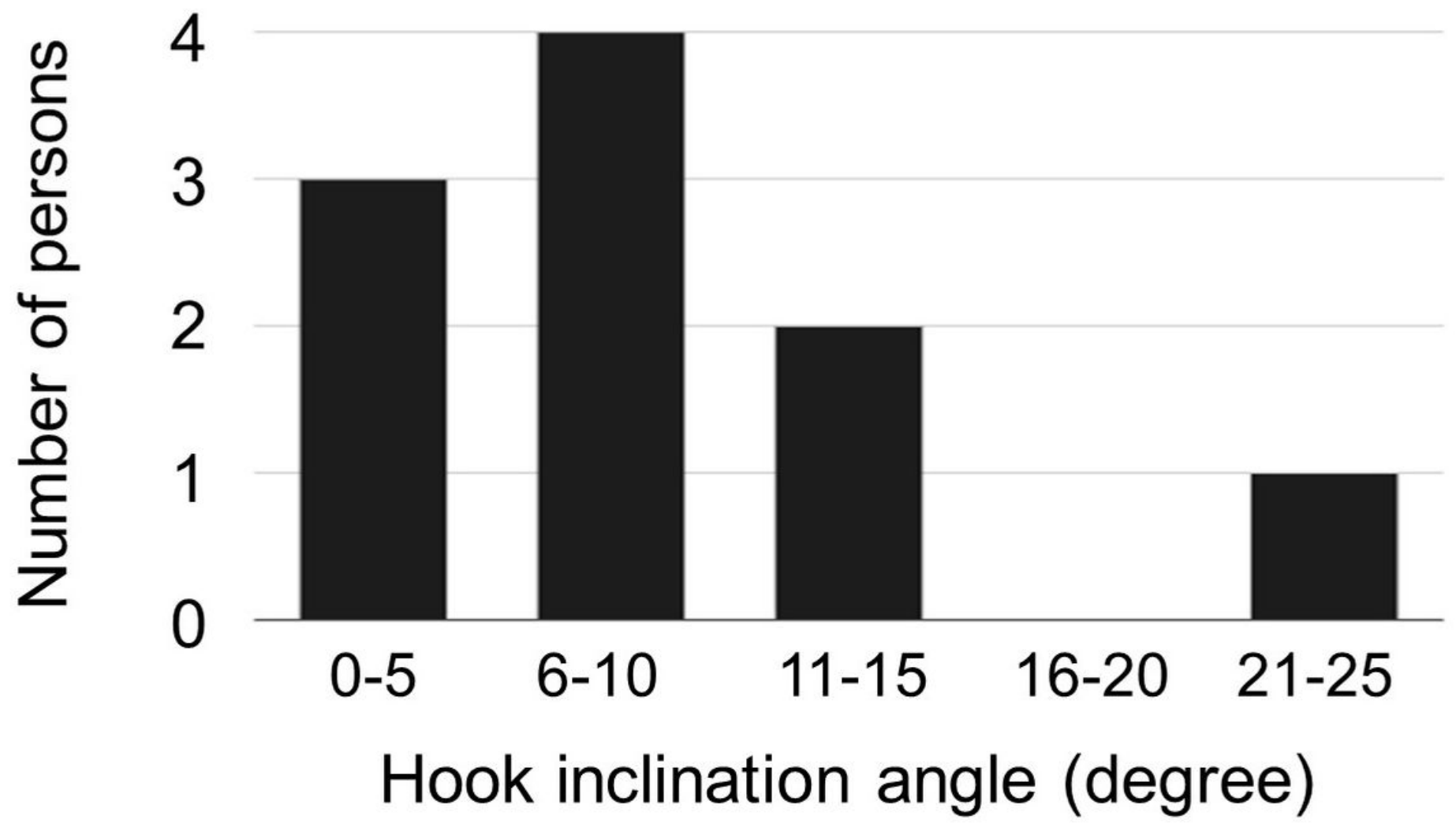

Figure 4

Histogram of the hook inclination angle for the patients in the bending group. 

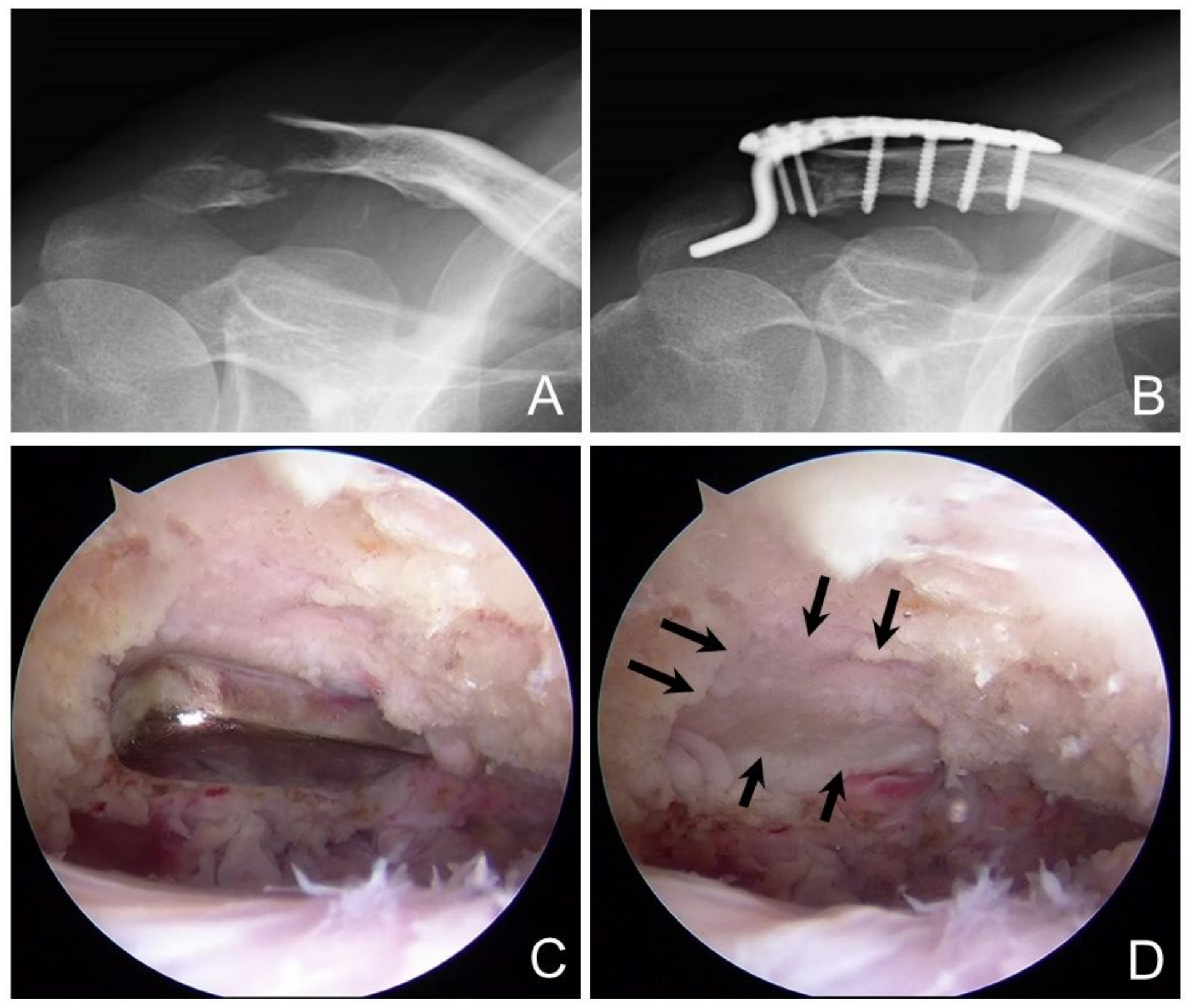

Figure 5

A 59-year-old man with a Craig type IIA distal clavicle fracture (bending group). Preoperative (A) radiograph and postoperative $(B)$ radiograph. During the operation, the hook was bent $16^{\circ}$ downward. At plate removal, (C) no rotator cuff injury was identified arthroscopically. (D) The size of the subacromial bony defect was $0 \mathrm{~mm}$. 

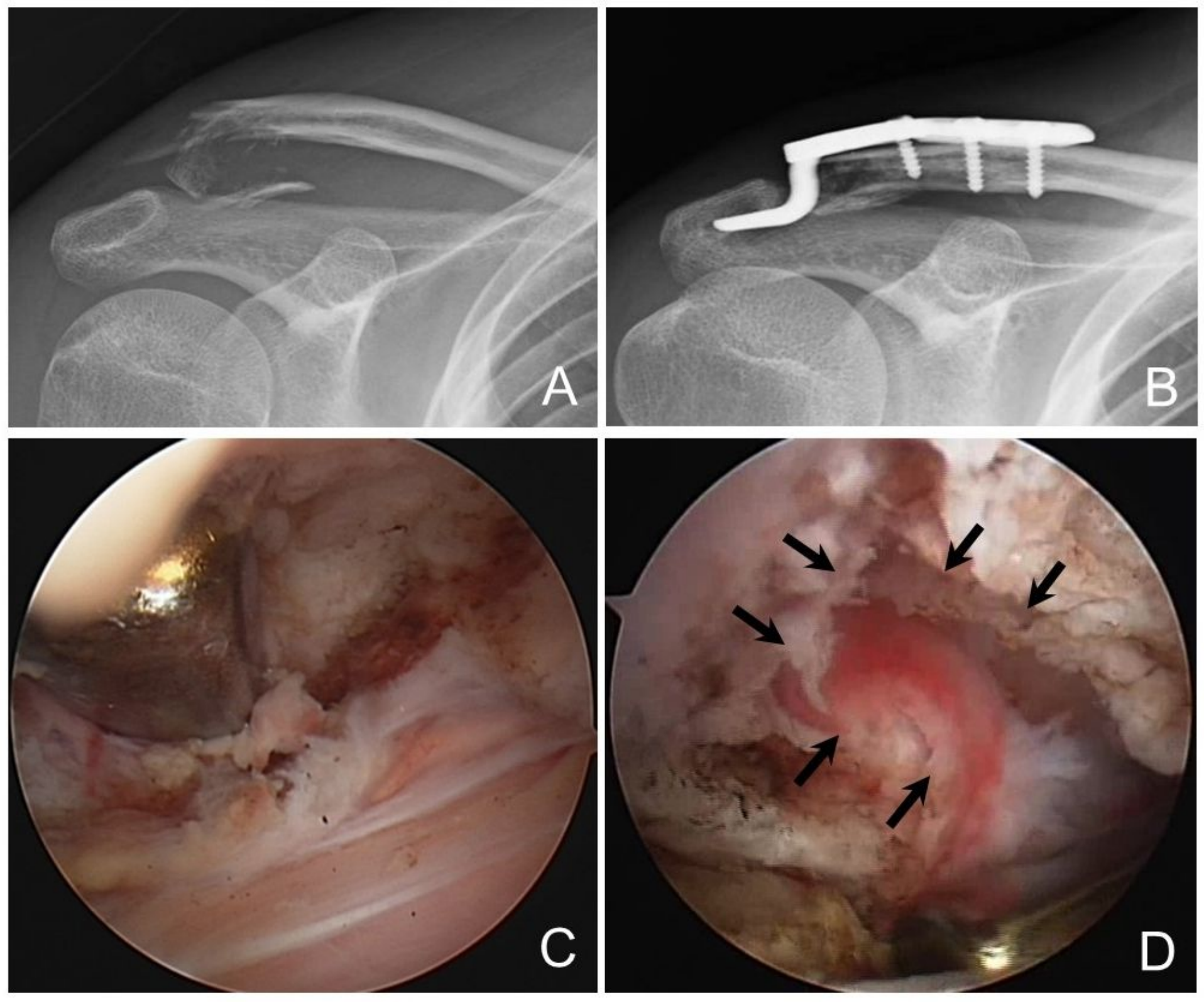

Figure 6

A 51-year-old man with a Craig type V distal clavicle fracture (nonbending group). Preoperative (A) radiograph and postoperative (B) radiograph. At plate removal, (C) a partial-thickness rotator cuff tear localized around the hook was observed arthroscopically. (D) The size of the subacromial bony defect was $8 \mathrm{~mm}$, and outgrowth of the synovial membrane was observed inside the bony defect.

\section{Supplementary Files}

This is a list of supplementary files associated with this preprint. Click to download.

- Table1.xls 